\title{
O MERCADO DE TRABALHO DA AGROINDÚSTRIA CANAVIEIRA: DESAFIOS E OPORTUNIDADES
}

\author{
Márcia Azanha Ferraz Dias de Moraes ${ }^{\S}$
}

\begin{abstract}
RESUMO
O crescimento da produção de açúcar e álcool, devido ao aumento do uso de álcool combustível, tanto no Brasil quanto para atender a demanda externa, bem como por causa do crescimento das exportações de açúcar, traz ótimas perspectivas para o setor. Contudo, a proibição da queima da cana-de-açúcar como método de despalha faz acelerar a mecanização da colheita, com impactos negativos sobre o número de empregados da lavoura canavieira, visto que serão criados empregos na indústria do açúcar e do álcool, mas haverá redução dos mesmos na área agrícola. Ademais, haverá mudança no perfil requerido do trabalhador agrícola, atualmente de baixa escolaridade. Em 2005, segundo a PNAD, havia 519.197 empregados na cultura da cana-de-açúcar do Brasil, cuja escolaridade média era de 3,9 anos de estudo; 70\% tinham até quatro anos de estudo e, destes, 154.598 podem ser considerados analfabetos funcionais (até 1 ano de estudo). Considerando-se que muitos são migrantes dos Estados mais pobres do Brasil, evidencia-se a necessidade de política pública nos locais de origem, dado o cenário de redução de demanda pelos trabalhadores de baixa escolaridade.
\end{abstract}

Palavras-chave: mercado de trabalho, proibição da queima de cana-de-açúcar, mecanização da colheita, indicadores sociais.

\begin{abstract}
The growth of the sugar and alcohol production due both to the increase in the use of alcohol fuel in Brazil, as well to meet the external demand, and because of the growth in exports of sugar, brings great prospects for the sugar alcohol sector. However, the ban of sugar cane burning as a method of detrash, does accelerate the mechanization of the harvest, with negative impacts on the number of employees of sugarcane production, since jobs will be created in the sugar industry and the alcohol, but there will be a greater reduction in the agricultural area. In addition, there will be change in the profile of the farm worker, currently of low schooling. In 2005, according to the PNAD, there were 519,197 employees in the culture of sugar cane in Brazil, whose school average was 3.9 years of study, $70 \%$ had up to four years of study, and of these, 154,598 can be considered illiterate (up to 1 year of study). Considering the fact that many workers are migrants from poorer states of Brazil, highlights the need for public policy at the place of origin, given the scenario of reduction of demand for workers with low education.
\end{abstract}

Key words: labor market, sugar-cane burning prohibition, harvesting mechanization, social indicators.

JEL Classification: J21, J43.

$\S \quad$ Profa. Dra. do Departamento de Economia, Administração e Sociologia da ESALQ/USP. E-mail: mafdmora@esalq.usp.br. Endereço para contato: Avenida Pádua Dias 11, Caixa Postal 9 - Departamento de Economia, Administração e Sociologia - ESALQ/USP - Piracicaba, SP - CEP 13400-970.

Recebido em setembro de 2007. Aceito para publicação em dezembro de 2007. 


\section{INTRODUÇÃo}

Mudanças institucionais importantes, tanto no Brasil como em outros países, resultaram numa nova fase de crescimento da agroindústria canavieira nacional, impulsionada por perspectivas de aumento da demanda tanto por açúcar como por álcool.

No âmbito internacional, uma maior consciência sobre a relação entre o uso de combustíveis fósseis e as mudanças climáticas incentivaram a procura pelo álcool combustível, dados os efeitos líquidos positivos na absorção de $\mathrm{CO}_{2}$. Internamente, o aumento das vendas de carros bicombustível, impulsionou a demanda pelo álcool hidratado, ocasionando reversão da tendência declinante do uso deste produto, que se verificou até meados de 2003.

Quanto ao mercado de açúcar, a vitória do Brasil, Austrália e Tailândia, importantes países produtores de açúcar, no painel aberto pelo Brasil na Organização Mundial do Comércio (OMC) sobre subsídios às exportações de açúcar branco praticados pela União Européia, sinalizou expansão da produção nos países competitivos, dentre os quais se destaca o Brasil.

Este novo crescimento da agroindústria canavieira tem impactos - positivos e negativos - em toda a cadeia produtiva do açúcar e do álcool, e sua sustentabilidade tem sido amplamente analisada. No que se refere aos impactos sobre o meio ambiente, citam-se os efeitos sobre a qualidade do ar nas áreas urbanas e rurais, sobre o clima global, sobre a oferta de água, ocupação e preservação do solo, emprego de agrotóxicos e fertilizantes.

Sob a ótica social, a despeito dos praticamente um milhão de empregos formais gerados somente nos três setores - cana-de-açúcar, açúcar e álcool - e apesar das perspectivas de geração de novos postos de trabalho nas indústrias do açúcar e do álcool devido à expansão do setor, muito tem se escrito sobre os empregos agrícolas - especificamente dos cortadores de cana-de-açúcar - principalmente sobre as condições de trabalho, ao pagamento por produtividade, ao uso da terceirização na contratação dos cortadores e da migração de trabalhadores de outros Estados, que vem principalmente para São Paulo para trabalhar no corte da cana-de-açúcar.

Além destes temas, duas mudanças institucionais internas relevantes sinalizam redução da colheita manual com conseqüente redução e mudança de perfil do empregado agrícola, visto que ambas aceleram o processo de mecanização da colheita: a primeira é a antecipação da proibição da queima no Estado de São Paulo e a outra é o efetivo cumprimento das normas regulamentadoras do mercado de trabalho agrícola no Brasil, por exemplo, a Norma Regulamentadora 31 (NR 31). Segundo estimativas da União da Agroindústria do Açúcar (UNICA), haverá redução de aproximadamente 114 mil empregados na lavoura canavieira até safra 2020/2021.

Portanto, dados a importante expansão deste setor, as mudanças institucionais recentes e os conseqüentes impactos sobre o mercado de trabalho, propõe-se neste artigo uma reflexão sobre o mercado de trabalho do setor de cana-de-açúcar, açúcar e álcool.

Neste trabalho, objetiva-se apresentar a evolução dos indicadores sociais deste setor e discutir os impactos das principais mudanças institucionais sobre mercado de trabalho, priorizando a discussão sobre o setor agrícola. 


\section{FONTE DE DADOS}

Os dados socioeconômicos foram extraídos da Pesquisa Nacional por Amostra de Domicílios (PNAD), ${ }^{1}$ do Instituto Brasileiro de Geografia e Estatística - IBGE (diversos anos) e dos Registros Administrativos do Ministério do Trabalho e Emprego (RAIS), ${ }^{2}$ do Ministério do Trabalho.

Os dados da PNAD foram extraídos para empregados da atividade cana-de-açúcar (código de atividade 01105). Para se analisar a evolução dos dados dos três setores (cana-de-açúcar, açúcar e álcool), utilizou-se como fonte de dados primários os Registros Administrativos do Ministério do Trabalho e Emprego (RAIS), do Ministério do Trabalho, cujo alcance é de 90\% deste setor organizado da economia e apresenta somente o emprego formal. Os dados foram extraídos para as classes 01139 (cultivo de cana-de-açúcar), 15610 (usinas de açúcar), 15628 (refino e moagem de açúcar) e 23400 (produção de álcool).

É importante observar que os dados de PNAD e dos RAIS não são comparáveis, visto que as metodologias da coleta dos dados de ambas diferem completamente: os RAIS constituem-se de censo do mercado formal de trabalho, sendo o questionário respondido pelo empregador, enquanto na PNAD a entrevista ocorre no domicílio do trabalhador. Neste caso, a unidade de análise é o estabelecimento, sendo que a resposta do entrevistado refere-se ao emprego na atividade principal do estabelecimento (ou seja, se na unidade agrícola existirem outras culturas, se a cana-de-açúcar for considerada pelo empregado a atividade principal, entende-se que é empregado do setor de canade-açúcar). Contudo, usualmente observa-se as mesmas tendências dos dados de ambas as bases.

\section{REVISÃO DE LITERATURA}

Nesta seção, procurou-se abordar as principais questões que influenciam o mercado de trabalho da agroindústria canavieira: a proibição da queima da cana-de-açúcar e o pagamento por produtividade.

\subsection{Proibição da queima da cana-de-açúcar como método de despalha}

Conforme Paes (2007), a queima da palha da cana-de-açúcar como método de despalha (eliminação da palha e folhas secas) é prática usual em quase todos os 97 países que a produzem. No Brasil, ainda é uma prática comumente usada na colheita manual da cana, que é realizada após o emprego do fogo para despalha, com posterior corte e transporte. A queima prévia da cana-de-açúcar aumenta a produtividade do trabalhador, porque evita a retirada da palha da cana.

1 A PNAD fornece um panorama da ocupação formal e informal do Brasil, sendo elaborada desde 1967 (de forma descontínua). Possui caráter amostral, sendo que seu desenho é estabelecido a partir do censo populacional de 1991 e de 2000, e permite a expansão dos resultados para todas as áreas do País.

2 A RAIS possui informações de caráter sociodemográfico e profissional, podendo ser agregada/desagregada ao longo dos eixos temporais (1986 a 2000) espaciais (nacional regional, estadual, municipal), econômico, natureza jurídica dos estabelecimentos empregadores e portes dos estabelecimentos. 


\subsection{Legislação sobre a queima da cana-de-açúcar}

As normas que regem a questão das queimadas são em âmbito federal, estadual e municipal. O Decreto Federal n ${ }^{\circ}$ 2.661, de 8/7/98, estabelece a eliminação gradual da queima da cana-deaçúcar. Conforme Paes (2007), são estabelecidas também as áreas de proibição de queima, como faixas de proteção nas proximidades de perímetros urbanos, rodovias, ferrovias, aeroportos, reservas florestais e unidades de conservação, entre outros.

Alguns Estados produtores estabeleceram normas específicas para tratar a eliminação da queimada, dentre eles Mato Grosso do Sul, Goiás, Paraná e São Paulo. Conforme Idea News (2007), no Mato Grosso do Sul, a Lei n ${ }^{\circ} 3.357$, de 9 de janeiro de 2007, estipula que a eliminação da queima deve acontecer num prazo de 20 anos, iniciando em 2006, num porcentual de 5\% ao ano. Nas áreas não mecanizáveis, a eliminação começa em 2010, na mesma proporção anual. Segundo a mesma fonte, em Goiás, a Lei no 15.834 , de 23/11/2006, estabelece a redução gradativa da queimada, com extinção total em 2028.

No Estado de Minas Gerais, por meio do Decreto $\mathrm{n}^{\circ}$ 39.792/98, que regulamenta a Lei Estadual $\mathrm{n}^{\mathrm{o}} 10.312 / 98$, é permitida a queima de forma controlada, com autorização prévia do órgão competente. No Paraná, existe um projeto de lei para proibir queimada até o final de 2010, aguardando votação na Câmara Estadual. Alagoas e Pernambuco, principais Estados produtores da região Norte/Nordeste, não têm legislação específica sobre o tema.

São Paulo, que na safra 2006/2007 foi responsável por 63\% de toda a cana-de-açúcar produzida no País, por 63,3\% da produção de álcool e por $65 \%$ da produção de açúcar, é o Estado que tem o menor prazo para a eliminação total da queima. A Lei Estadual no 10.547, de 2 de maio de 2000, estipula os procedimentos, proibições, regras de execução e medidas de precaução a serem tomados quando do emprego do fogo em práticas agrícolas. Nos termos da lei, é necessário que, antes do emprego do fogo, o interessado requeira ao poder público a expedição de "Autorização de Queima Controlada”, sendo a Secretaria do Meio Ambiente responsável para expedir a referida autorização.

Em setembro de 2002, foi promulgada a lei $\mathrm{n}^{\mathrm{o}} 11.241$, que estipula um cronograma gradativo de extinção da queima da cana-de-açúcar, iniciado na safra 2002, e determinando que tal prática deve ser totalmente banida neste Estado até o ano de 2021 em áreas mecanizáveis, e até 2031 em áreas não mecanizáveis. Contudo, em junho de 2007, foi assinado um protocolo de cooperação entre o governo do Estado de São Paulo e a União da Agroindústria de São Paulo - UNICA - denominado Protocolo Agroambiental, que visa à antecipação da eliminação da queima no Estado de São Paulo. Apesar de o protocolo não ter força de lei, ou seja, não substituir a Lei Estadual $\mathrm{n}^{\circ}$ 11.241, e não ser obrigatório as usinas aderirem ao mesmo, houve grande aceitação e a expectativa é que a grande maioria das usinas assine o protocolo. ${ }^{3}$

A principal mudança advinda do protocolo refere-se ao prazo para a eliminação da queima. As usinas e produtores que aderirem ao mesmo deverão antecipar, nos terrenos com declividade até 12\%, o prazo final para eliminação da queimada, de 2021 para 2014, adiantando o porcentual de cana não queimada, em 2010, de $50 \%$ para $70 \%$. Nos terrenos com declividade acima de $12 \%$, o prazo final é de 2031 para 2017, adiantando o porcentual, em 2010, de $10 \%$ para $30 \%$. Outras medidas

3 O Grupo Cosan, que detém 17 usinas de açúcar e álcool, foi o primeiro a assinar o Protocolo Agroambiental no dia 21/9/2007, na cidade de Piracicaba. Em 2007, o Grupo Cosan colhe cerca de 40\% de sua cana sem o emprego do fogo. Até 2001, pretendese chegar a 80\%, com investimentos de US $\$ 100$ milhões na compra de 200 colheitadeiras (Jornal de Piracicaba, 22/9/2007, p. A-7). 
referem-se à não utilização da queima na área de expansão de canaviais; não permitir queima de subprodutos (por exemplo, bagaço de cana) a céu aberto; proteger as matas ciliares; proteger e reflorestar as nascentes; desenvolver plano de conservação do solo e dos recursos hídricos; adotar boas práticas para o descarte de embalagens vazias e minimizar a poluição atmosférica na indústria.

Ainda no Estado de São Paulo, tem havido diversas tentativas, por meio de promulgação de leis municipais e ações civis públicas, visando à proibição imediata das queimadas. Citam-se as cidades de Americana, Ribeirão Preto, Limeira, Paulínia, São José do Rio Preto, Botucatu, São José do Rio Pardo. Embora na maioria dos casos tenham sido revogadas por meio de Ações Diretas de Inconstitucionalidade (ADINs), interpostas contra as Leis Municipais que proíbem a queima de cana, fica claro que parcela da sociedade requer que a eliminação da queima aconteça antes mesmo dos prazos estipulados pela legislação pertinente.

Contudo, é importante lembrar que existe um balanço entre a redução das queimadas e o número de empregados envolvidos com a colheita manual da cana-de-açúcar: a proibição da queima induz à mecanização, processo que tende a se acelerar a partir de agora, com a antecipação dos prazos para eliminação da queima.

A produtividade do trabalhador com a colheita da cana crua manual cai muito (em média de 6 toneladas por dia por empregado para 3 toneladas por dia por empregado), o que inviabiliza a adoção desta prática em ambiente de livre mercado. A colheita mecânica da cana crua é economicamente mais eficiente, dados os menores custos de produção, além do fato de as próprias convenções coletivas de trabalho estipularem que o corte manual deve ser de cana queimada, dadas as dificuldades encontradas no corte manual da cana crua.

Conforme Paes (2007), a mecanização da colheita foi implantada no Brasil na década de 1980, e vem crescendo por três fatores principais: em meados da década de 1980, pela escassez de mãode-obra ocorrida durante o Plano Cruzado e, mais recentemente, pela redução de custos e pela pressão ambiental para que a colheita da cana seja feita sem queimar. Segundo o autor, no Estado de São Paulo, em 1997, a proporção da colheita mecanizada era ao redor de 18\%, tendo alcançado $42 \%$ em 2006. Na região Centro-Sul, este porcentual foi de 35\% em 2006 e, da mesma forma que para o Estado de São Paulo, observa-se tendência crescente de mecanização. Na região Norte-Nordeste, a proporção de colheita mecanizada é bem menor, ao redor de $10 \%$.

É interessante observar que, no Estado de São Paulo, a velocidade de adoção da colheita mecanizada varia bastante entre as principais regiões produtoras do Estado - Ribeirão Preto e Piracicaba: enquanto na região de Ribeirão Preto estima-se que a mecanização tenha atingido em torno de $60 \%$ da colheita, em Piracicaba esta proporção é ao redor de $20 \%$. Este fato pode ser explicado por diversos fatores: (i) a região de Ribeirão Preto é plana, favorecendo a mecanização com as máquinas atualmente disponíveis, enquanto mais de $70 \%$ das terras de Piracicaba têm declividade superior a 30\%; (ii) a estrutura fundiária entre ambas também é diferente - enquanto na região de Ribeirão Preto existe a predominância de grandes produtores, com escala que justifica a compra de uma máquina colhedora, em Piracicaba a grande maioria é de pequenos produtores, que não são capitalizados para adquirirem colhedeiras mecânicas, além de não terem escala de produção eficiente para a colheita mecânica; (iii) o movimento sindical dos trabalhadores na região de Ribeirão 
Preto tem maior grau de organização, com elevado poder de barganha, ${ }^{4}$ tendo incentivado a adoção da colheita mecânica bem antes da legislação entrar em vigor.

A tendência de mecanização da colheita, principalmente na região Centro-Sul, é irreversível e tende a se acelerar por diversos motivos. Além dos anteriormente citados, nos anos recentes, as usinas estão investindo em co-geração de energia elétrica a partir da queima de bagaço de cana, para comercialização de energia neste mercado. Além do bagaço, a palha também pode ser utilizada como matéria-prima para a co-geração de energia elétrica, o que estimula as usinas a deixarem de queimá-la.

Portanto, além dos fatores institucionais - a legislação proibindo a queima da cana-de-açúcar e a aplicação mais efetiva da legislação trabalhista - a mecanização tende a se acelerar também em função do aumento de competitividade das usinas, principalmente com o desenvolvimento de colheitadeiras menores, mais baratas e com tecnologia que permita a colheita em terrenos com maior declividade.

\subsection{Impactos sobre o emprego}

A questão que emerge é que a mecanização da colheita altera o perfil do empregado: cria oportunidades para tratoristas, motoristas, mecânicos, condutores de colheitadeiras, técnicos em eletrônica, dentre outros, e reduz, em maior proporção, a demanda dos empregados de baixa escolaridade (grande parte dos trabalhadores da lavoura canavieira têm poucos anos de estudo), expulsando-os da atividade. Este fato implica a necessidade de alfabetização, qualificação e treinamento desta mão-de-obra, para estar apta a atividades que exijam maior escolaridade.

Segundo estimativas da UNICA, sem se considerar os funcionários envolvidos na gestão e administração da produção, no Estado de São Paulo, entre as safras de 2006/2007 e 2020/2021, o número de empregados envolvidos com a produção de cana-de-açúcar, açúcar e álcool passará de 260,4 mil para 146,1 mil, ou seja, haverá uma redução de 114 mil empregos neste período, conforme exposto na Tabela 1.

Observa-se que na indústria é esperado um aumento de 20 mil empregados, enquanto na lavoura canavieira o número passará de 205,1 mil empregados para 70,8 mil, ou seja, uma queda de 134,3 mil. A previsão é que não haja colheita manual na safra 2020/2021. Para que parte dos empregados agrícolas sejam realocados para as atividades do corte mecânico, é necessário escolaridade maior do que a da grande maioria dos empregados.

4 Conforme Ricci et al. (1994), na região de Ribeirão Preto, a greve dos colhedores de cana em 1984, quando $100 \%$ da cana era colhida manualmente, paralisou as usinas de açúcar e mostrou a força dos trabalhadores e a dependência das empresas. Desde então, houve incentivo para a adoção gradual da colheita mecanizada.

5 Uma colheitadeira substitui ao redor de 80 cortadores de cana. 
Tabela 1 - Estimativas da redução do número de empregados dos setores de cana-de-açúcar, açúcar e álcool no Estado de São Paulo

\begin{tabular}{lrrrr}
\hline & $2006 / 07$ & $2010 / 11$ & $2015 / 16$ & $2020 / 21$ \\
\hline Produção cana-de-açúcar (milhos t) & 299 & 370 & 457 & 544 \\
Área colheita mecânica & $40 \%$ & $70 \%$ & $100 \%$ & $100 \%$ \\
Número empregados (mil empregados) & & & & \\
Colheita manual & 189,6 & 107,4 & 0 & 0 \\
Colheita mecânica & 15,5 & 30,8 & 59,5 & 70,8 \\
Indústria & 55,3 & 62,6 & 68,3 & 75,3 \\
Total (mil empregados) & 260,4 & 200,8 & 127,8 & 146,1 \\
\hline
\end{tabular}

Fonte: UNICA, ${ }^{6} 2007$.

Guilhoto et al. (2002) estudaram os impactos diretos e indiretos sobre o emprego, utilizando um modelo inter-regional de insumo-produto para a economia brasileira de 1997, nas cinco macrorregiões, considerando especificamente o setor de cana-de-açúcar.

Os autores consideraram dois cenários possíveis: (i) mecanização de $50 \%$ da colheita na região Norte-Nordeste e $80 \%$ na região Centro-Sul, sem alteração dos níveis de produtividade; (ii) mesmas hipóteses, alterando-se a produtividade - aumento de $20 \%$ tanto para a colheita manual como mecânica. Os autores encontraram que a redução do número de empregados devido à mecanização da colheita são de aproximadamente 243 mil no cenário I e 273 mil no cenário II. Ao se considerar o nível de escolaridade, os autores encontraram que as maiores perdas serão justamente para aqueles empregados com até três anos de estudo.

Tanto inovações tecnológicas quanto mudanças no ambiente institucional têm impactos importantes sobre o emprego. Ricci et al. (1994) destacam que, na área agrícola, podem ser citados três níveis de inovação tecnológica com impactos sobre o mercado de trabalho: (i) inovações mecânicas - afetam a intensidade e ritmo da jornada de trabalho; (ii) inovações físico-químicas - modificam as condições naturais do solo e elevam a produtividade do trabalho; (iii) inovações biológicas - interferem na velocidade de rotação do capital e do trabalho.

Os autores citam os principais impactos decorrentes das inovações mecânicas na lavoura canavieira: redução do tempo das tarefas realizadas, redução da demanda por mão-de-obra, redução da mão-de-obra residente na propriedade e mudança qualitativa na demanda por trabalhadores; já que as novas atividades - tratorista, motoristas, operadores de máquinas - requerem maior grau de especialização dos trabalhadores.

Em São Paulo, conforme informação dos sindicatos patronais, atualmente o carregamento, transporte e cultivo da cana-de-açúcar são $100 \%$ mecanizados, sendo a colheita aproximadamente $40 \%$ mecanizada. Portanto, a colheita, que em média representa $30 \%$ do custo de produção da cana-de-açúcar, ainda utiliza um grande contingente de homens e máquinas (guinchos, caminhões).

6 Apresentação feita pelo presidente da entidade, Marcos Sawaya Jank, durante o Fórum Internacional do Álcool, em Sertãozinho/SP, em 17/9/2007. 


\subsection{Pagamento por produção}

Outra questão que faz parte da agenda de discussões do mercado de trabalho do setor de açúcar e álcool é a forma de pagamento da colheita da cana-de-açúcar que, atualmente, é o pagamento por produção. Além da cana-de-açúcar, outras atividades agrícolas também adotam o pagamento por produtividade, tais como algodão, amendoim, café, laranja, limão e tangerina.

A remuneração por produção tem ampla base legal: é prevista no artigo $457, \S 1^{\underline{0}}$ da Consolidação das Leis do Trabalho (CLT), bem como tem incontroversa aceitação doutrinária e jurisprudencial. Da mesma forma, é prevista em normas coletivas de trabalho, para diversas culturas. ${ }^{7}$ Desde 1984, com a criação do "Grupo Cana”, passaram a existir as convenções e acordos de trabalhos específicos para o setor canavieiro, cujas normas estipulam: piso salarial, remuneração do bituqueiro, reajustes salariais, valor da tonelada de cana de 18 meses, e outros cortes e cláusulas sociais específicas.

A limitação existente é que deve ser garantido ao trabalhador um salário mensal nunca inferior ao mínimo, conforme o Artigo 78 da CLT.

Contudo, apesar de ser previsto pela legislação aplicável, e estar presente em vários acordos coletivos de trabalho, diversos autores têm questionado o pagamento por produtividade dos empregados da lavoura canavieira.

Balsadi (2007) indica melhorias em diversos indicadores socioeconômicos ao longo do tempo, tais como a redução do trabalho infantil, o aumento do nível de formalidade, os ganhos reais de salário, o aumento de alguns benefícios recebidos e o aumento da escolaridade dos empregados. O autor salienta o elevado porcentual de trabalhadores com carteira assinada, o que possibilita acesso à aposentadoria, e destaca que a cultura da cana-de-açúcar é uma das atividades com maior nível de formalidade do emprego. Basaldi também trata dos ganhos reais de salários entre 1992 e 2005 que, segundo o autor, considerados os dados da PNAD, foram de 34,5\% para os empregados permanentes com residência urbana, de 17,6\% para os permanentes rurais, de 47,6\% para os temporários urbanos e de 37,2\% para os temporários rurais. Ainda de acordo com o autor, ao longo do tempo, aumentaram os benefícios recebidos pelos trabalhadores, tais como crescimento dos auxílios transporte e alimentação para todas as categorias, além do auxílio moradia para os residentes rurais e do auxílio saúde para os empregados permanentes com residência urbana.

Porém, Balsadi (2007) destaca que, apesar das melhorias dos indicadores citados, ainda existem condições adversas principalmente para os empregados temporários ocupados na colheita manual da cana-de-açúcar, e também têm ocorrido mortes de trabalhadores nos canaviais. $\mathrm{O}$ autor cita diversas reportagens de jornal que associam as mortes ao sistema de pagamento por produtividade. Da mesma forma, Alves (2006) associa este sistema de pagamento às mortes nos canaviais.

Até o momento não existem estudos científicos que demonstrem o nexo causal entre a forma de pagamento e as mortes anteriormente citadas. Porém, no Estado de São Paulo, o Ministério Público do Trabalho da $15^{\mathrm{a}}$ Região, responsável por 600 municípios de São Paulo, anunciou em 2006 que pretendia entrar com uma ação civil pública para tentar eliminar na Justiça o sistema de remuneração por produção para o pagamento dos empregados da lavoura canavieira, por acreditar que o mesmo pode ser o causador das mortes de cortadores de cana-de-açúcar.

7 Por exemplo, a Convenção Coletiva de Trabalho "Setor Citricultura", no Estado de São Paulo, firmada por 20 Sindicatos Profissionais Rurais e pela Federação de Agricultura do Estado de São Paulo - FAESP, para o período de 1/7/2006 a 30/6/2007. 
O fim do pagamento por produção não é consensual entre os sindicatos profissionais, visto que existe parcela de trabalhadores que é a favor do mesmo. A UNICA (conforme publicado no Estado de São Paulo, 14/9/2006, caderno B-11) é contrária ao fim do pagamento por produção, porém destaca que a entidade busca nas usinas garantir o efetivo cumprimento das normas vigentes, visando ao pagamento correto dos cortadores conforme estipulado nas convenções coletivas de trabalho.

\section{RESUlTADOS: EVOLUÇÃO DOS INDICADORES SOCIAIS}

Inicia-se a análise com a evolução do número de trabalhadores formais envolvidos na produção de cana-de-açúcar, açúcar e álcool, para as duas regiões produtoras e o total do Brasil, para os anos de 2000 a 2005. Nota-se pela Tabela 2 que, para o Brasil como um todo, entre 2000 e 2005, considerando-se os três setores (cana-de-açúcar, açúcar e álcool) conjuntamente, houve aumento expressivo de 52,9\% do número de empregados, que passou de 642.848 em 2000 para 982.604 em 2005, em conformidade com o crescimento do setor. Em 2005, ao redor de 63\% dos empregados formais estavam na região Centro-Sul do País.

Tabela 2 - Número de empregados da agroindústria por região produtora - 2000 a 2005

\begin{tabular}{lccccc}
\hline Região Produtora & 1981 & 2001 & 2002 & 2004 & 2005 \\
\hline NNE & 250.224 & 302.720 & 289.507 & 343.026 & 364.443 \\
CS & 392.624 & 433.170 & 475.086 & 557.742 & 618.161 \\
\hline Total Brasil & 642.848 & 735.890 & 764.593 & 900.768 & 982.604 \\
\hline
\end{tabular}

Fonte: Elaborado a partir de MT-b Rais, vários anos.

A Tabela 3 traz o número de empregados formais por região produtora e por setor: canade-açúcar, açúcar e álcool. Percebe-se que o crescimento dos empregados formais das usinas de açúcar $(101,9 \%)$ e destilarias de álcool $(88,4 \%)$ do Brasil foi maior do que o dos trabalhadores rurais $(16,2 \%)$ envolvidos com a produção de cana-de-açúcar, provavelmente em decorrência do processo de mecanização da colheita de cana. É importante observar que, neste período, houve crescimento da produção de cana-de-açúcar: em 2000, a produção nacional foi de 325,33 milhões de toneladas e, no de 2005, foi de 419,56 milhões (Ministério da Agricultura, Pecuária e Abastecimento, 2005); ou seja, um crescimento da produção da ordem de 28,9\%. Nota-se também que, em 2000, ao redor de $55 \%$ do total eram empregados rurais e, em 2005, sua participação caiu para 42,2\%.

Considerando-se a distribuição por Estado, de forma agregada para os três setores, tem-se, conforme os dados dos RAIS, que 39,2\% dos empregados eram do Estado de São Paulo, seguidos por Pernambuco (15\%), Alagoas (14,1\%), Paraná (7\%), Minas Gerais $(5,6 \%)$, Goiás $(3,6 \%)$, Mato Grosso $(2,6 \%)$ e Mato Grosso Sul $(2,4 \%)$. Os demais Estados tinham individualmente menos de $2 \%$ dos empregados. 
Tabela 3 - Número de empregados formais por região produtora e por setor - 2000 a 2005

\begin{tabular}{llccccc}
\hline & Região & 2000 & 2001 & 2002 & 2004 & 2005 \\
\hline \multirow{2}{*}{ Cana-de- } & NNE & 81.191 & 97.496 & 86.329 & 104.820 & 100.494 \\
Açúcar & CS & 275.795 & 302.830 & 281.291 & 283.301 & 314.174 \\
\cline { 2 - 7 } & Total Brasil & 356.986 & 400.326 & 367.620 & 388.121 & 414.668 \\
\hline \multirow{3}{*}{ Açúcar } & NNE & 143.303 & 183.517 & 174.934 & 211.864 & 232.120 \\
& CS & 74.421 & 84.920 & 126.939 & 193.626 & 207.453 \\
\cline { 2 - 7 } & Total Brasil & $\mathbf{2 1 7 . 7 2 4}$ & $\mathbf{2 6 8 . 4 3 7}$ & $\mathbf{3 0 1 . 8 7 3}$ & $\mathbf{4 0 5 . 4 9 0}$ & 439.573 \\
\hline \multirow{3}{*}{ Álcool } & NNE & 25.730 & 21.707 & 28.244 & 26.342 & 31.829 \\
\cline { 2 - 7 } & CS & 42.408 & 45.420 & 66.856 & 80.815 & 96.534 \\
\hline \multirow{2}{*}{ Total Brasil 3 setores } & $\mathbf{6 8 . 1 3 8}$ & $\mathbf{6 7 . 1 2 7}$ & 95.100 & 107.157 & 128.363 \\
\hline
\end{tabular}

Fonte: Elaborado a partir de MT-b Rais, vários anos.

A seguir, são analisados os dados para o Estado de São Paulo, o maior produtor nacional. Os dados dos RAIS captam somente o emprego formal e, dada a alta informalidade da agricultura nacional, não trazem informações sobre grande parcela dos empregados. Contudo, para o Estado de São Paulo, informações da PNAD indicam que a formalidade do setor de cana-de-açúcar era de aproximadamente $94 \%$ em 2005, razão pela qual considera-se factível o uso dos RAIS para análise dos dados dos empregados da lavoura canavieira para São Paulo. A Tabela 4 apresenta distribuição dos empregados formais para São Paulo em 2005, por setor e por idade.

Observa-se que, em 2005, aproximadamente 57,2\% dos 385.533 empregados eram da produção de cana-de-açúcar, seguidos pelos da indústria do açúcar $(34,2 \%)$ e pelos da indústria do álcool $(8,6 \%)$.

Ao se considerar a faixa etária dos 220.517 empregados agrícolas, observa-se que a maior proporção $(28,4 \%)$ tinha entre 30 a 39 anos, seguidos pelos empregados de 18 a 24 anos $(25,3 \%)$ e 25 a 29 anos (19,3\%). Nota-se proporção considerável (17,6\%) de empregados na faixa de 40 a 49 anos.

Tabela 4 - São Paulo: número de empregados e faixa etária da produção de cana-de-açúcar, açúcar e álcool - 2005

\begin{tabular}{lcrrr}
\hline Idade & Cana-de-açúcar & Açúcar & Álcool & Total \\
\hline Até 17 anos & 513 & 249 & 41 & 803 \\
18 a 24 anos & 55.813 & 32.585 & 7.329 & 95.727 \\
25 a 29 anos & 42.483 & 24.705 & 5.963 & 73.151 \\
30 a 39 anos & 62.677 & 37.777 & 9.694 & 110.148 \\
40 a 49 anos & 38.830 & 25.174 & 6.662 & 70.666 \\
50 a 64 anos & 18.580 & 10.600 & 3.234 & 32.414 \\
65 ou mais & 1.621 & 777 & 226 & 2.624 \\
Total & 220.517 & 131.867 & 33.149 & 385.533 \\
\hline
\end{tabular}

Fonte: Elaborado a partir de MT-b Rais, vários anos. 
Para se analisar a evolução dos indicadores sociais da produção de cana-de-açúcar no Brasil, optou-se por analisar os dados da PNAD, que captam tanto o emprego formal quanto o informal.

A Tabela 5 traz a evolução do número de empregados da lavoura canavieira do Brasil, por regiões e para São Paulo. Considerando-se os dados para o Brasil, observa-se uma redução de 16,9\% no número total de empregados entre 1981 e 2005, a despeito do crescimento importante da produção de cana, que passou de aproximadamente 133 milhões de toneladas na safra 1981/1982 para 386,6 milhões de toneladas na safra 2005/06 (aumento de 190\%). Este fato pode ser explicado pelo aumento da produtividade do trabalhador e principalmente pela mecanização da colheita da canade-açúcar, que aumenta a demanda por mão-de-obra qualificada e reduz, em maior proporção, a demanda por empregados com escolaridade menor. A análise dos dados para São Paulo indica que o número de empregados agrícolas manteve-se praticamente constante entre 1981 e 2005 (de 154.751 para 153.719), mas neste período o crescimento da produção foi de aproximadamente $245 \%$ (passou de 70,4 milhões para 242,8 milhões de toneladas de cana), indicando menor número de empregados por tonelada colhida.

Quanto à formalização (empregados com carteira assinada entendidos como formais e sem carteiras como informais), nota-se que a participação dos empregados formais do setor de cana-deaçúcar no Brasil tem aumentado ao longo do tempo. Considerando-se os dados agregados para o Brasil, estes passaram de 37,2\% em 1981 para 72,9\% em 2005. A região Norte-Nordeste, em 1981, tinha 35,1\% de empregados formais, em 2005, aumentou para 60,8\%; na região Centro-Sul a proporção foi de 40,7\% em 1981 para 85,8\% em 2005. O Estado de São Paulo, o maior produtor de cana-de-açúcar do Brasil, apresentou os melhores indicadores: a formalização passou de 40,5\% em 1981 para 93,8\% em 2005. Pode-se notar que, embora a formalidade esteja aumentando de forma geral, o número de empregados informais (aproximadamente 100 mil trabalhadores) ainda é muito elevado na região Norte-Nordeste.

A evolução dos salários médios para três períodos distintos, separados por região produtora, e a escolaridade média dos empregados da cana-de-açúcar para o Estado de São Paulo encontram-se na Tabela 6. 


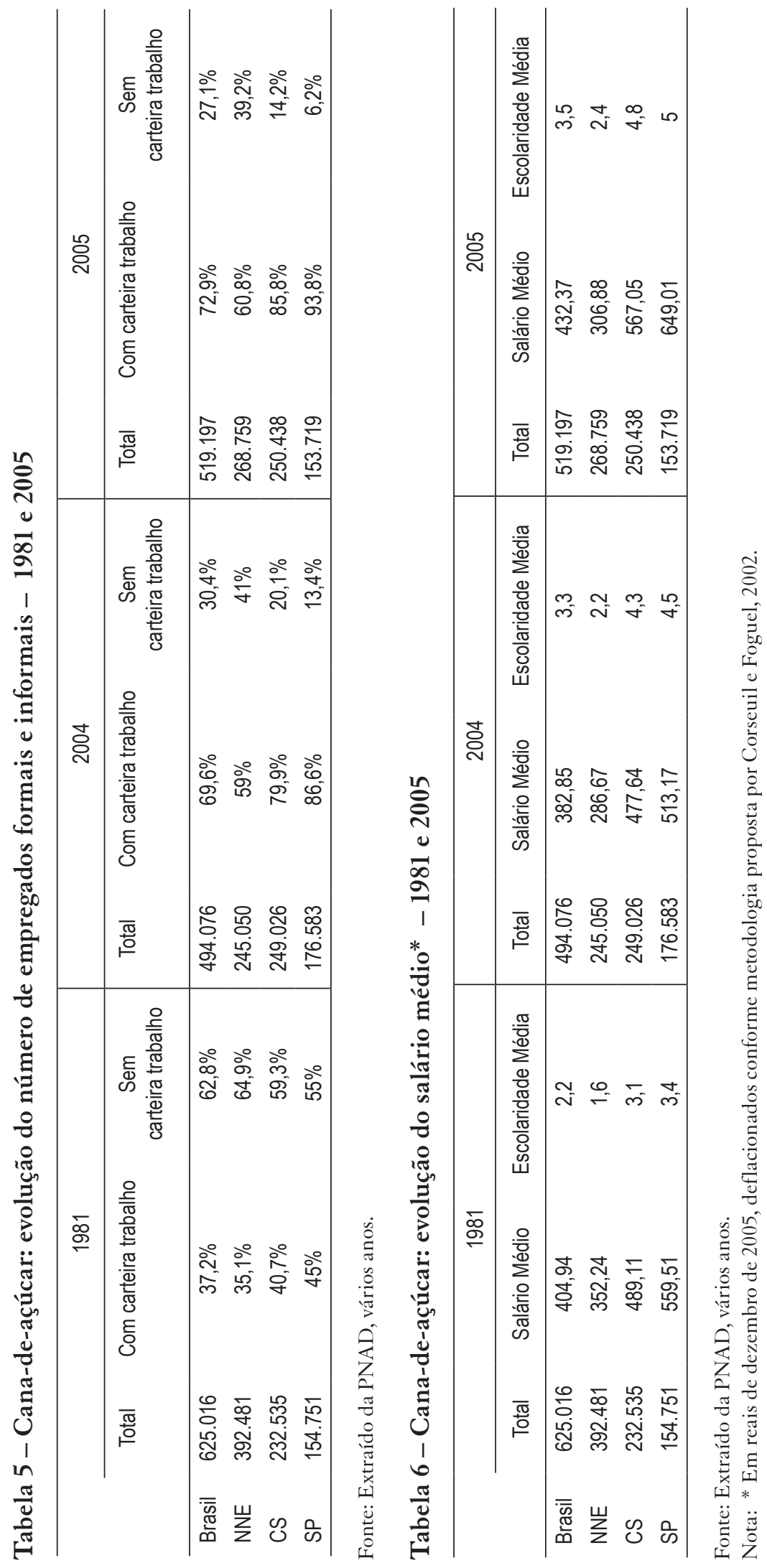


Observa-se que a escolaridade média dos trabalhadores em 2005 é de 3,5 anos de estudo, e que, apesar de ser baixa, a escolaridade tem evoluído positivamente para o Brasil e também para todas as regiões analisadas. Em São Paulo, a escolaridade média em 2005 foi de aproximadamente 5 anos. Nota-se que os salários são positivamente correlacionados com a escolaridade média.

Em relação aos salários médios, verifica-se que em São Paulo eles são mais altos que as demais regiões em todos os períodos. Em 2005, o salário médio pago em São Paulo, de R \$649,01, foi $50 \%$ maior que o salário médio do Brasil como um todo, e mais do que o dobro do salário médio da Região Norte-Nordeste.

A Tabela 7, por sua vez, apresenta a evolução do número de empregados por faixa de anos de estudo para o Brasil como um todo. Observa-se que em 1981 a grande maioria dos empregados $(95,4 \%)$ tinha até 4 anos de estudo, sendo que aproximadamente 355 mil trabalhadores podiam ser considerados analfabetos funcionais, pois declararam ter até 1 ano de estudo. Observa-se importante melhora deste quadro ao longo do período analisado, visto que em 2005 os empregados analfabetos representavam $29,8 \%$.

Apesar da evolução positiva no nível de escolaridade dos trabalhadores do setor de cana-deaçúcar no Brasil entre 1981 e 2005 - a escolaridade média passou de 2,2 anos de estudo para 3,9 - ressalta-se que ainda é muito baixo: 70,1\% dos empregados da lavoura de cana-de-açúcar do Brasil em 2005 tinham até 4 anos de estudo, sendo que 29,8\% (ou seja, 154.598 empregados) podem ser considerados analfabetos funcionais (declararam ter até 1 ano de estudo).

Em São Paulo, para o ano de 2005, a escolaridade era mais alta, mas ainda existia grande número de empregados com poucos anos de estudo. Do total de 153.719 empregados, 28.504 empregados tinham até 1 ano de estudo, que representavam 18,6\% do total. Destes, 21.593 eram analfabetos. Na faixa de 2 a 4 anos de estudo incompletos, existiam 29.358 empregados e, com 4 anos completos, eram 29.364. Num cenário de maior mecanização neste Estado, que requer empregados com escolaridade maior, observa-se que um grande número de pessoas não estará qualificado para as novas posições.

Tabela 7 - Cana-de-açúcar: evolução do número de empregados no Brasil por faixa de anos de estudo

\begin{tabular}{lcc|cc}
\hline Educação & \multicolumn{2}{c|}{1981} & \multicolumn{2}{c}{2005} \\
\cline { 2 - 5 } Anos de estudo & Número de empregados & $\%$ total & Número de empregados & $\%$ total \\
\hline Até 1 ano & 355.180 & 56,8 & 154.598 & 29,8 \\
2 a 4 incompletos & 177.398 & 28,4 & 121.656 & 23,4 \\
4 completos & 63.845 & 10,2 & 87.681 & 16,9 \\
Até 7 & 15.210 & 2,4 & 73.270 & 14,1 \\
8 completos & 7.245 & 1,2 & 30.278 & 5,8 \\
Até 10 & 4.509 & 0,7 & 16.534 & 3,2 \\
11 completos & 1.289 & 0,2 & 29.299 & 5,6 \\
12 ou mais & 340 & 0,1 & 5.881 & 1,1 \\
\hline Total & 625.016 & 100 & 519.197 & 100 \\
\hline
\end{tabular}

Fonte: Elaborado a partir de dados da PNAD data, vários anos. 


\section{CONCLUSÕES}

A expansão da agroindústria canavieira, impulsionada pelo uso do álcool combustível em substituição à gasolina no Brasil e em outros países, bem como pela expectativa de aumento das exportações de açúcar em decorrência da redução das políticas protecionistas da União Européia, colocou este setor em evidência tanto interna como externamente.

Espera-se o surgimento de muitas oportunidades para profissionais qualificados e, numa análise de equilíbrio geral, haverá uma dinamização da economia em muitas indústrias de insumos e no setor de serviços, o que abre excelentes oportunidades para estes profissionais.

Neste ambiente de crescimento, mais do que nunca as questões ambientais e sociais vêm à tona, e são diariamente discutidas nos meios acadêmicos, jornais, televisão e outros veículos de comunicação. No lado social, o debate foca-se principalmente nas condições de trabalho dos cortadores de cana-de-açúcar e no sistema de pagamento por produção. A discussão, sob ótica ambiental, versa principalmente sobre a possibilidade de destruição da Floresta Amazônica e outros biomas, e sobre a questão das queimadas.

Contudo, parece que o tradeoff entre a proibição da queima e o desaparecimento do emprego no corte de cana-de-açúcar foi, até o momento, pouco analisado.

Não se trata de defender a volta da queima da cana-de-açúcar como método de despalha. A mudança está dada e a sociedade reclama pela sua extinção. Da mesma forma, ninguém há de ser contrário ao cumprimento da legislação e normas trabalhistas existentes pelos produtores de canade-açúcar, sejam eles a indústria do açúcar e do álcool ou fornecedores de cana.

O que se procura trazer para reflexão neste artigo é a falta de escolaridade dos mais de cem mil empregados da cultura da cana-de-açúcar que perderão seus empregos. Ainda que esta quantidade possa estar superestimada, metade deste valor ainda é um número muito alto.

Ao lado dos bons indicadores sociais - praticamente eliminação do trabalho infantil, aumento da formalização - a escolaridade, apesar de ter evoluído positivamente ao longo do tempo, ainda é muito baixa. Existe um grande contingente de empregados analfabetos no corte da cana-de-açúcar. E parte destes vem de outras regiões para trabalhar em São Paulo, onde encontram trabalho na lavoura da cana.

Por que um trabalhador sai de sua região de origem, muitas vezes deixando esposa e filhos, para enfrentar este trabalho que, apesar de importante e ser o sustento de sua família, é árduo e difícil? Provavelmente porque ele não encontra trabalho na sua cidade ou Estado de origem.

E quais ações e políticas públicas estão sendo feitas para enfrentar este problema social de grande porte? Muitas empresas no Estado de São Paulo já implantaram programas de alfabetização e requalificação de parte da mão-de-obra visando à adequação em outras atividades. Mas não é suficiente. É importante que se inicie a discussão sobre as políticas públicas, principalmente nas regiões de origem, necessárias para lidar com tema tão complexo. 


\section{REFERÊNCIAS BIBLIOGRÁFICAS}

ALVES, F. J. C. Por que morrem os cortadores de cana? Saúde e Sociedade. v. 15, n.3, p. 90-98, set-dez 2006.

ANTECIPAR o fim da queimada: problema ou solução? Idea News, n. 80, jun. 2007.

BALSADI, O. O mercado de trabalho assalariado na cultura da cana-de-açúcar. Dossie Ethanol. Revista Eletrônica da SBPC, n. 86. Disponível em:. <http://www.comciencia.br/comciencia>. Acesso em: 10 abr. 2007.

BRASIL. Ministério do Trabalho e Emprego. Registros Administrativos. RAIS, vários anos. CD-ROM.

CORSEUIL, C. H.; FOGUEL, M. N. Uma sugestão de deflatores para rendas obtidas a partir de algumas pesquisas domiciliares do IBGE. Rio de janeiro: IPEA. 2002. (Texto para discussão n. 897).

GUILHOTO, J. J.; BARROS, A. L. M.; MARJOTTA-MAISTRO, M. C.; ISTAKE, M. Mechanization process of the sugar cane harvest and its direct and indirect impact over the employment in Brazil and in its 5 macro regions. São Paulo: IPE-USP, 2002. (Texto de Seminários, IPE-USP, n. 09/2002).

INSTITUTO de Desenvolvimento Agroindustrial. Idea News. Ribeirão Preto. 2007

PAES, L. A. D. Emissões nas queimadas de cana, controle. In: Macedo, I. C. (org). A energia da canade-açúcar. Doze estudos sobre a agroindústria da cana-de-açucar no Brasil e sua sustentabilidade. 2a. ed. São Paulo: Berlendis \& Vertecchia: UNICA, 2007. p. 85-89.

PNAD. Pesquisa nacional por amostra de domicílios. Rio de Janeiro: IBGE, vários anos. CD-ROM.

RICCI, R; ALVES, F. J. C.; NOVAES, J. R. P. Mercado de trabalho do setor sucroalcooleiro no Brasil. Brasília: IPEA, 1994. 176p. (Estudos de Política Agrícola. Documentos de Trabalho, 15. Projeto PNUD/BRA/91/014) 